This item was submitted to Loughborough's Research Repository by the author.

Items in Figshare are protected by copyright, with all rights reserved, unless otherwise indicated.

\title{
Directives: entitlement and contingency in action
}

PLEASE CITE THE PUBLISHED VERSION

http://dx.doi.org/10.1177/1461445610370126

PUBLISHER

SAGE $\odot$ The Author(s)

VERSION

AM (Accepted Manuscript)

LICENCE

CC BY-NC-ND 4.0

REPOSITORY RECORD

Craven, Alexandra, and Jonathan Potter. 2019. "Directives: Entitlement and Contingency in Action". figshare. https://hdl.handle.net/2134/15123. 
This item was submitted to Loughborough's Institutional Repository (https://dspace.lboro.ac.uk/) by the author and is made available under the following Creative Commons Licence conditions.

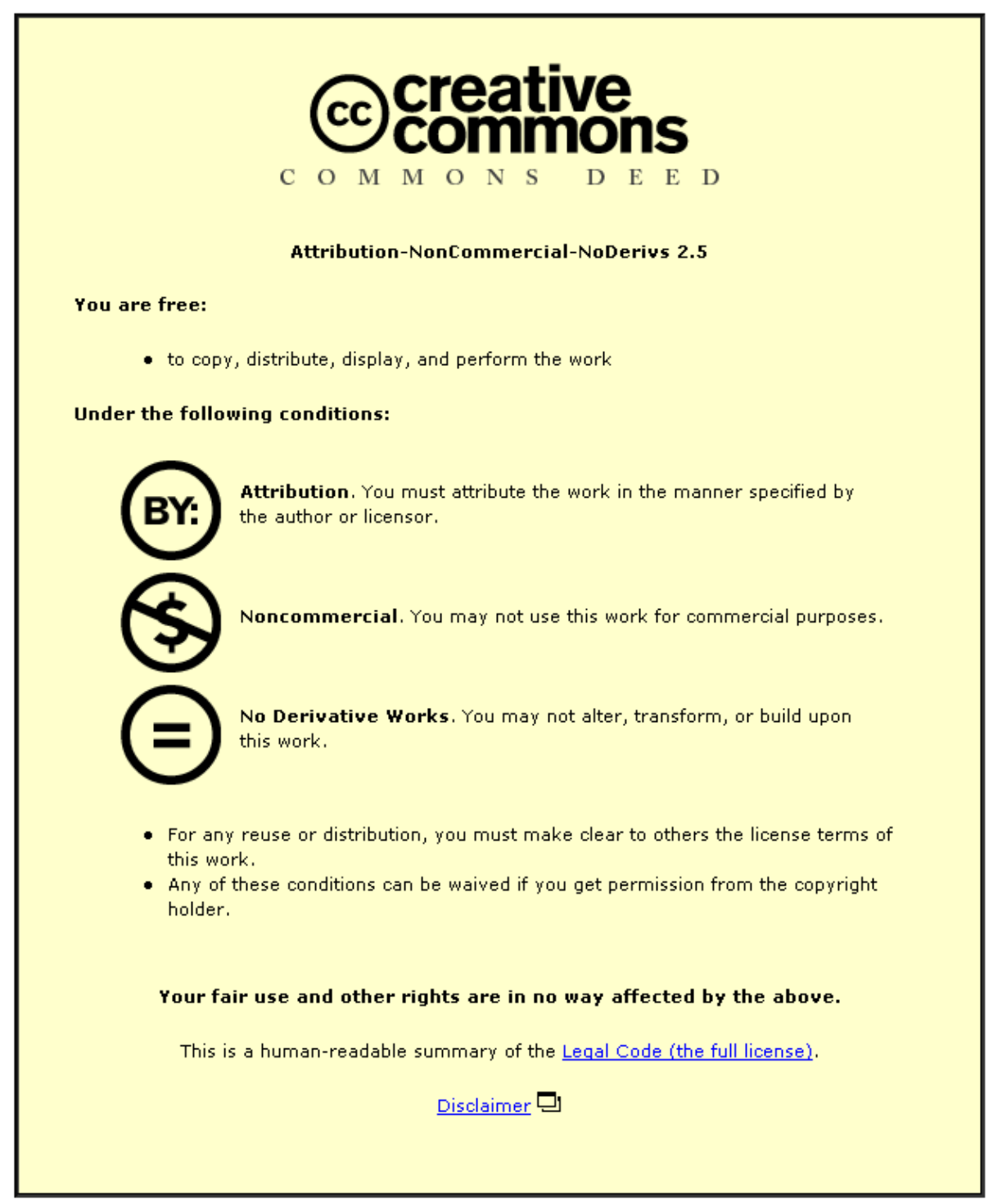

For the full text of this licence, please go to: http://creativecommons.org/licenses/by-nc-nd/2.5/ 


\section{Directives: Entitlement and contingency in action}

\section{Alexandra Craven* and Jonathan Potter}

Discourse and Rhetoric Group

Department of Social Sciences

Loughborough University

Loughborough

Leicestershire, LE11 3TU

UK

Published as:

Craven, A. \& Potter, J. (2010). Directives: Entitlement and contingency in action,

Discourse Studies, 12, 419-422. DOI: 10.1177/1461445610370126

The authors would like to thank the members of the Discourse and Rhetoric Group at Loughborough University, particularly Alexa Hepburn, Charles Antaki and Laura Jenkins for helpful discussions in data sessions. We would also like to thank Kobin Kendrick, Candy Goodwin, Paul Drew, Traci Walker (nee Curl) and an anonymous reviewer for their important critical and constructive contributions. Finally we would like to thank the participants for giving up their time for the research. 


\section{Biographical notes}

ALEXANDRA CRAVEN is doing doctoral research in the Social Sciences Department at Loughborough University. Her research interests include family mealtime interaction, laughter, the negotiation of power and authority in interaction, children's talk, and parenting practices. She is an active participant in the Discourse and Rhetoric Group at Loughborough University and is the Editorial Assistant for 'Research on Language and Social Interaction'.

JONATHAN POTTER is Professor of Discourse Analysis and Head of the Department of Social Sciences at Loughborough University. He has studied racism, argumentation, fact construction and topics in social science theory and method. His most recent books include: Representing Reality, which attempted to provide a systematic overview, integration and critique of constructionist research in social psychology, postmodernism, rhetoric and ethnomethodology and Conversation and Cognition (with Hedwig te Molder) in which a number of different researchers consider the implication of studies on interaction for understanding cognition. He is one of the founders of discursive psychology. 


\title{
Directives: Contingency and Entitlement in Action
}

\begin{abstract}
This paper is focused on the nature of directives. It draws on Curl and Drew's (2008) analysis of entitlement and contingency in request types and applies this to a corpus of directives that occur in UK family mealtimes involving parents and young children (3-8yrs old). While requests are built as contingent to varying degrees on the recipient's willingness or ability to comply, directives embody no orientation to the recipient's ability or desire to perform the relevant activity. This lack of orientation to ability or desire may be what makes them recognisable as directives. When examining directives in sequence the contingencies were successively reduced or managed during the delivery of the directive, thereby treating contingencies as a resource of the speaker rather than of the recipient. In a sense the entitlement claimed is 'to tell' rather than 'to ask'. In sequences involving multiple / repeated directives, non-compliance led to upgraded (more entitled and less contingent) directives. The difference in the entitlement claimed, the response options available and the trajectory of multiple requests/directives suggests participants orient to requests and directives as different actions, rather than more or less forceful formulations of the same.
\end{abstract}

Key words: Directives, requests, family interaction, conversation analysis, mealtimes, eating, socialisation, discursive psychology. 


\section{INTRODUCTION}

This paper focuses on directives. In her important overview, that builds on Austin (1962), Blum-Kulka (1996), Ervin-Tripp (1976) and Labov and Fanshell (1977), Goodwin glosses directives as 'utterances designed to get someone to do something' (Goodwin, 2006: 517). This description fits with Searle's (1979) sense of the 'illocutionary point' of directives in his discussion of Speech Act Theory; it has also become an accepted way of characterising directives by subsequent researchers (e.g. Vine, 2009). However, such a description leaves the boundaries of what should be counted as a directive relatively open; for example, it does not clearly distinguish a directive from a request. Indeed, Searle includes 'requests, orders, commands, askings, prayers, pleadings, beggings and entreaties' within his category of directives (1979: 5). While Curl and Drew (2008) characterise a request as an action in which one participant asks another to do something, we will treat a directive as an action where one participant tells another to do something.

Much of the existing research literature into request types has tended to organise them along a spectrum according to how direct they are (Curl \& Drew, 2008). The directness of a request has most commonly been judged by analysts according to its level of politeness (Aronsson \& Thorell, 1999). Such an approach tends to treat requests and directives as versions, of varying politeness, of the same action. In Searle's terms, the difference between a request and a directive may not involve a difference in illocutionary point; rather it will be a function of a difference in the 'style of performance of the illocutionary act' (1979: 8, original emphasis).

There has been a larger body of research into more indirect or polite forms of request than into the more direct forms, which will occupy our analysis here. Indeed, Goodwin has noted that explicit imperatives have been considered 'obvious' and not in 
need of analytic interpretation (1990: 83). This may account for the relative lack of interest in directives up to now. She suggests that we should not assume that direct imperatives are immune from the 'issues of understanding' that are more evident when requests are built in a less direct manner, perhaps to avoid causing offence (Goodwin, 1980: 84). In this paper we will follow her advice.

Ervin-Tripp (1976) offers one of the most comprehensive and influential studies of requests and directives. Using material from a range of different environments she proposed a typology of different types of directives:

- Need statements, such as 'I need a match'.

- Imperatives, such as 'Gimme a match' and elliptical forms like 'a match'

- Imbedded imperatives, such as 'Could you gimme a match?' In these cases, agent, action, object, and often beneficiary are as explicit as in direct imperatives, though they are embedded in a frame with other syntactic and semantic properties

- Permission directives, such as 'May I have match?' Bringing about the condition stated requires an action by the hearing other than merely granting permission.

- Question directives, such as 'Gotta match?' which do not specify the desired act.

- Hints, such as 'The matches are all gone' (1976: 29).

Ervin-Tripp further suggested that a speaker's choice between such alternatives is dependent on 'the relative power of speaker and addressee' (1976: 29). This theme is developed in more recent work by Goodwin (1990), Fasulo et al (2007) and Wingard (2006). Although such work shows that there is a relationship between directives and various power asymmetries, the patterning is complex. It is clear, for example, that parents issue actions 
which have the character of requests on some occasions but have more the character of demands on others. Wootton (1997) highlighted considerable complexity in his study of imperatives, and both Ervin-Tripp (1976) and Goodwin (1990) have emphasised the key importance of local sequential position in understanding the operation of a directive.

In the analysis that follows we will draw on Curl and Drew's (2008) work that analyses different types of requests based on the entitlement they display over the actions of the recipient and their orientation to the contingencies that affect acceptance. A central feature of their approach was to highlight the way requests can be built differently, and understood differently, in varying environments. In particular, they suggested that the form of request type was chosen according to (a) the entitlement of the request issuer to what the request demands and (b) to the range of contingencies for the request recipient in delivering what is requested. Request forms become more presumptuous when the person requesting claims high entitlement and treats the recipient as likely to be able to comply with the request (low contingency).

They focused on two request forms; modal verbs (e.g. can you) and requests prefaced with 'I wonder if...'. Although they found some broad association of these forms with institutional environments: modals were more common among family members, wonderings in calls to a doctor's surgery, they also found the key determinant in the choice of which form was used was whether the person issuing the request treated her or himself as having a strong entitlement to what was requested and whether the recipient was straightforwardly able to satisfy the request (entitlement and contingency).

Curl and Drew's (2008) notion of entitlement focuses on the speaker's grounds for assessing the likelihood of the request being granted and their concomitant display of their right to make the request. Contingency relates to the recipient's ability or willingness to 
grant the request. These are two very similar concepts where, put simply, entitlement relates to the speaker and contingency to the recipient.

Curl and Drew argue that the modal form displays more entitlement than requests prefaced with 'I wonder if...' and therefore tends to be used where: 'the requester has (and can show) good reason for thinking his or her request reasonable and easily granted and therefore more common among family members' (2008: 148). They conclude by emphasising the value of considering requests on a continuum of contingency and expectation/entitlement where the two dimensions are inversely linked such that high entitlement requests contain few (if any) contingency markers. Similarly, strongly contingent requests show minimal expectation of acceptance or entitlement to make the request in the first place.

We note that it is not a simple matter of using a modal versus a wondering. The wonderings appear as prefaces to requests which themselves typically use modals. For example (from Curl and Drew, 2008: 138):

1 Doc Hello,

2 Clr mt! Hello, I wonder if you could give me some advice, More schematically the form is wondering + modal request ('I wonder if' + 'you could give me some advice'). The wondering form has the effect of changing the grammar so the recipient is not being asked about their capacity. Instead, the speaker's 'wondering' about their capacity is 'simply' reported. These formulations take the form, then, of my-side tellings (Pomerantz, 1980). These classically operate by the speaker reporting 'their side' of some relevant matter where the recipient has their 'own side'. This works as a practice for fishing for a response rather than directly asking for one. Such formats, according to Pomerantz (1980), display a careful orientation to the recipient's 'own side' as being 'their business'. Wonderings contrast with directives, of course, even more starkly. In a 
wondering the recipient is neither being told what to do, as is the case with directives, nor being asked if they can do something, as is the case with requests; rather the wondering generates an environment where a wondering may be satisfied (or not).

A notable feature of Curl and Drew's (2008) 'Entitlement and Contingency' approach to studying requests is that it is not dependent on prior judgements of politeness or authority and it offers a way of making sense of the relationship between turn design and features of local context. We will draw on this approach when we consider different features of the design of directives.

Like previous researchers, we found a wide variety of different ways of formulating directives. This, we suggest is due to inexact relationship between grammatical form and social action. The prototypical grammatical form for a directive would probably be an imperative. However, Huddleston \& Pullum note that even imperatives fail to offer a clear mapping of action onto grammar: the construction can be used to cover "offers (Have a pear), requests (Please pass me the salt), invitations (Come to dinner), advice (Get your doctor to look at it), instructions (To see the picture click here) and so on" (2005: 8). Moreover, they also note that a range of different grammatical forms can be used to issue directives. Part of the aim of using entitlement and contingency in our approach is to clarify this complex organization. In the analysis that follows we will extend Curl and Drew's (2008) focus on entitlement and contingency in requests to a corpus of directives that occurred where families with young children were gathered together to eat. This is part of a broader programme of work that considers eating, action, and family interaction (Hepburn \& Potter, under editorial consideration). 


\section{DATA AND ANALYSIS}

The data for the present study came from a corpus of video recordings of family mealtimes. The criteria for selection were that they (a) had two or more pre-teenage children; (b) were first language English speakers; (c) ate meals around a table and (d) did not watch television or listen to the radio during mealtimes. The aim was to have material in which there was interaction between both parents and children in all combinations, where there were a range of ongoing and coordinated embodied actions and where the parties would be static enough to be captured using a single video camera. All participating families were given a camera and asked to film meals as they felt happy and able to. They had the option of not recording or deleting any meal before submission to the researcher for any reason. The collection is ongoing, but the sample for this study consisted of 28 meals averaging around half an hour each.

Our general interest in studying families with young children stems partly from the paucity of child centred family research in both the fields of Sociology of the Family and in analyses of Adult-Child Interaction. Much of the sociological research into domestic life has concentrated on gender and has tended to explain its findings in terms of gender differences and discrimination. Lareau notes that 'much of the empirical work is descriptive', yielding generalised impressions rather than clear, repeatable findings (2002: 748). In particular, the literature lacks a focus on children as active participants in conversation in their own right. Grieshaber (1997) points out that despite the pervasive evidence that parents tried to get their children to eat properly there has been little discussion about exactly how this was done. Studies instead more often simply commented that mealtimes were a site of parental authority and childhood rebellion (e.g. Charles \& 
Kerr, 1985). Within this broad set of topics the current paper will focus on directives, mostly but not exclusively, issued by parents to children.

Our analytic approach will draw heavily on contemporary conversation analysis (Drew, 2008; Hutchby \& Wooffitt, 2008; Schegloff, 1996). At the same time we will be guided by discursive psychological principles in considering the role of cognition or psychological states in unfolding action (Edwards, 1997; Edwards \& Potter, 2001).

\begin{abstract}
ANALYSIS
Directives

If we extrapolate from Curl and Drew's (2008) analysis of entitlement and contingency in request sequences to directive sequences, we would expect to find strong markers of entitlement and little or no acknowledgement of contingencies that could thwart compliance. The imperative is built as a telling rather than asking. As such it displays strong entitlement by 'pointedly not orient[ing] to any possibility of the request not being granted' (Curl \& Drew, 2008: 145). Extracts 1-4 provide some examples of directives using an imperative.
\end{abstract}

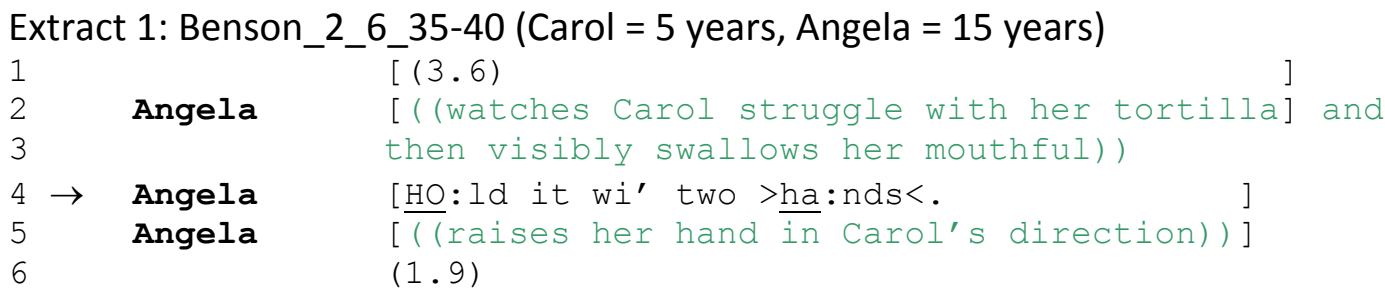



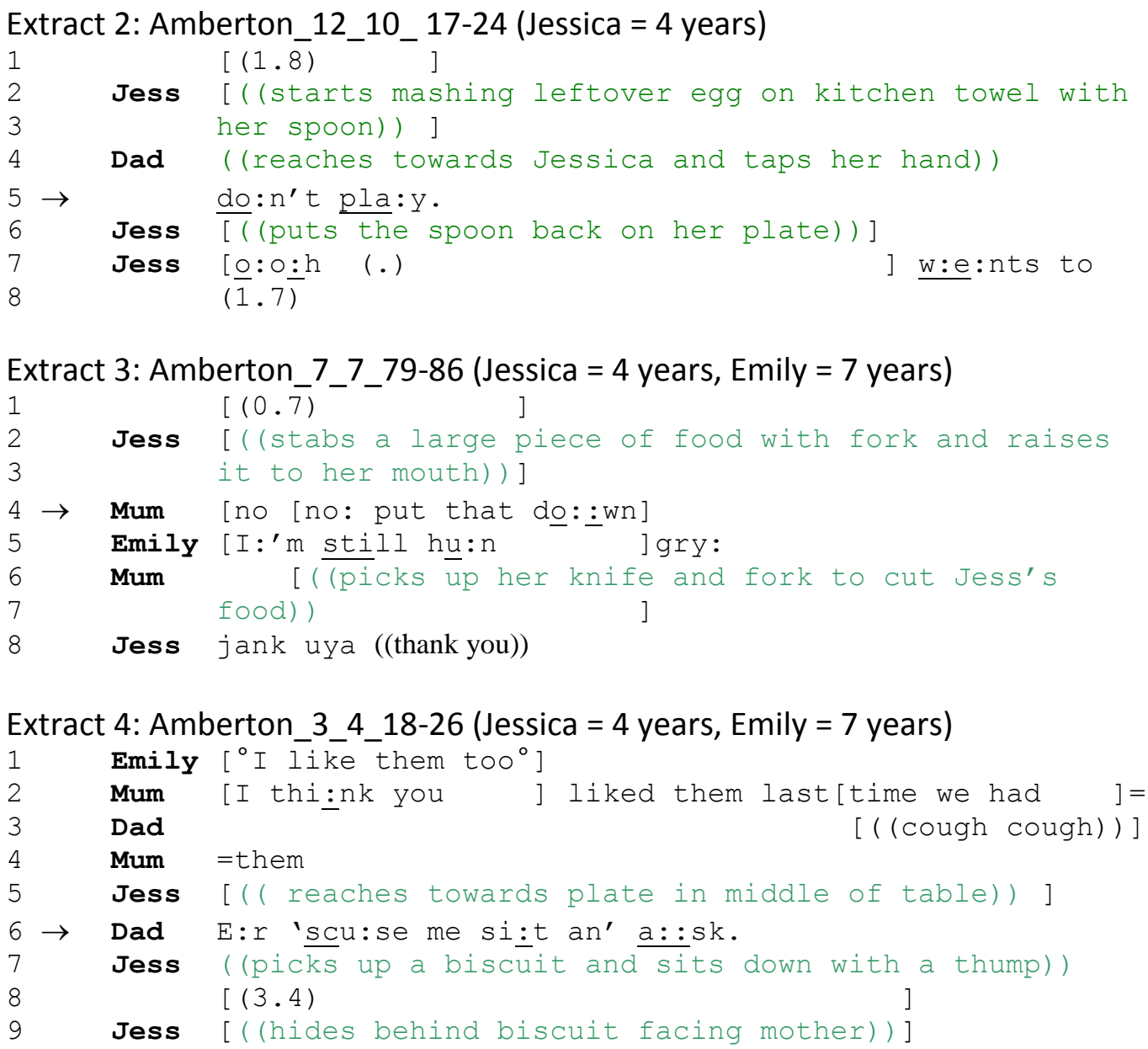

In each of the arrowed turns a change in the recipient's conduct is specified. This gives us the core sense of the turn as directive - it directs the recipient in some way (to do something such as hold a tortilla with both hands while eating it, or desist in doing something such as playing with leftover egg). Linguists would describe the directions to desist as 'prohibitive' (van der Auwera et al, 2008).

Note that none of the examples here uses a modal construction. Thus the directive in Extract 1 for example is built:

$\underline{\mathrm{HO}}:$ ld it wi' two >ha: nds $<$.

It is not built with a modal form such as:

Could you $\underline{\mathrm{HO}}:$ ld it wi' two $>$ ha: nds $<$. 
That is, Extract 1 does not build a request using the form of an interrogative addressed to Carol about her capacity to hold the tortilla with both hands.

Secondly, note that none of the examples was prefaced with a wondering construction. Thus Extract 1 was not built:

I'm wondering if you could $\underline{\mathrm{HO}}$ : ld it wi' two $>\underline{\text { ha }}$ : nds $<$.

That is, Extract 1 does not build a request by reporting a wondering about the recipient's capacity to hold the tortilla with both hands.

Our data highlights the point that any modal forms using 'can' or 'will' or 'could' treats compliance with the request, at least formally, as contingent on the recipient's ability or willingness to comply (Vine, 2009). Requests built in such a way can be refused, just as Daisy's request for more cheese is refused by Mum in Extract 5 below.

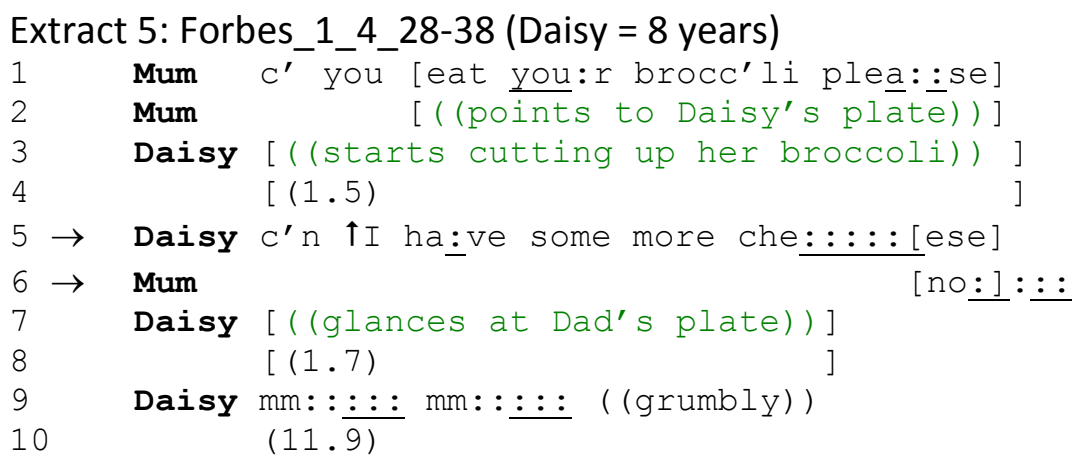

Here Mum's refusal of the request is delivered unproblematically (line 6) and Daisy accepts the refusal, offering no further attempts to have her request granted. Her only response is a quiet grumble as an aside rather than a turn built to require a response (line 9).

Interestingly, refusing a request would typically be considered a dispreferred response, of which we might expect to see markers such as delay, hesitation or elaboration (Pomerantz, 1984, Schegloff, 2007). In this case, Mum's response is immediate, even slightly pre-emptive, unequivocal, and unelaborated. She displays no trouble refusing 
Daisy's request. Her stretched out no: : : sound mimics Daisy's exaggerated intonation on che: : : : :ese. This may help to moderate the abrupt nature of the refusal. The lack of formal features of dispreference might also be a consequence of the asymmetry between young child and parent. However, these are not the issues for the current paper.

While requests are in some way contingent on the recipient's willingness or ability to comply, what is striking about our collection of directives is that they embody no orientation to the recipient's ability to perform the stated activity. Thus “ $\underline{\mathrm{HO}}:$ Id it wi' two $>$ ha : nds $<$ " does not orient to Carol's ability or willingness to hold the tortilla in this way.

Beyond embodying no verbal orientation to ability or willingness, directives can be further designed to restrict and manage the possible contingencies that could prevent compliance. For example, in Extract 1, Angela's directive to Carol that she " $\underline{\mathrm{HO}}$ : ld it wi" two $>$ ha : nds $<$ " is synchronised with a physical demonstration of two hands raised. This specifies the required action and provides an example of how to act in order to comply with the directive. By providing the example, rather than asking if one is needed, Angela restricts Carol's ability to refuse to comply on the grounds of misunderstanding or lack of ability. Similarly, in Extract 4, Mum's directive to Jessica to put down the large piece of food she is nibbling from her fork is accompanied by a move to cut up the food. This removes Jessica's ability to account for her eating style by claiming the mouthful is too big to eat in one go. The embodied conduct is built to further constrain what the recipient does.

In contrast to requests, in these examples of directives contingencies are not alluded to or acknowledged. Instead they are removed or managed in conjunction with issuing the directive. Put another way, the design of the directive does not orient to non-compliance as a response option. Modal requests orient (at least formally) to the recipient's willingness or 
capacity to comply. In so doing they project the possibility of refusal. Requests have to be accepted before they can be performed; directives just need to be complied with. In this respect requests and directives are performing two different actions.

In addition to restricting the contingencies available to the recipients, the imperative formulation enables speakers to display entitlement to direct the recipient's actions. What we see in directives is one person involving him or herself with another's business without asking, or even reporting a wondering, about their willingness or capacity (with a modal construction or 'I wonder if...' preface). The imperative formulation tells, it does not ask. This means that, unlike a question or a request, the directive does not make acceptance relevant as a next action; as Goodwin (2006) shows, the next action it makes relevant is compliance.

Put another way, the directive construction does not treat the recipient's acceptance as a relevant issue. By not requiring acceptance, the speaker positions her or himself as fully entitled to direct the recipient. It literally treats the recipient as not having a say in their own conduct. Although Curl and Drew (2008) note that modal forms of requests display high entitlement to what is requested, by virtue of their lack of concern with acceptance, directives display an even more heightened entitlement.

Our basic suggestion, then, is that directives show high entitlement to direct the other speaker and little or no orientation to the contingencies on which the compliance with the directive may rest. Accordingly, directives can be understood as both projecting only compliance and fully restricting the optionality of the recipient's response. This does mean of course that recipients may not fail to comply or may not select different options than those specified in the directive. The point is that these alternatives are not projected in the construction of the directive. 


\section{Multiple Directives}

Through focussing on contingency and entitlement, Curl and Drew (2008)

demonstrated that request forms can change during a single stretch of interaction as the dimensions of contingency and entitlement fluctuate with the provision of new information. They show that speakers may renegotiate contingency and entitlement when building requests while the sequence unfolds and that participants orient to swift changes in both dimensions when reformulating requests that have not been granted.

We examined sequences containing multiple directives in terms of their changes in entitlement and contingency. The general pattern in our data is that the multiple directives upgrade the issuer's entitlement and downgrade the recipient's contingency. We will first consider two cases to illustrate this pattern, and then discuss its implications. Extract 6, includes 3 versions of a request/directive modified in the face of resistance.

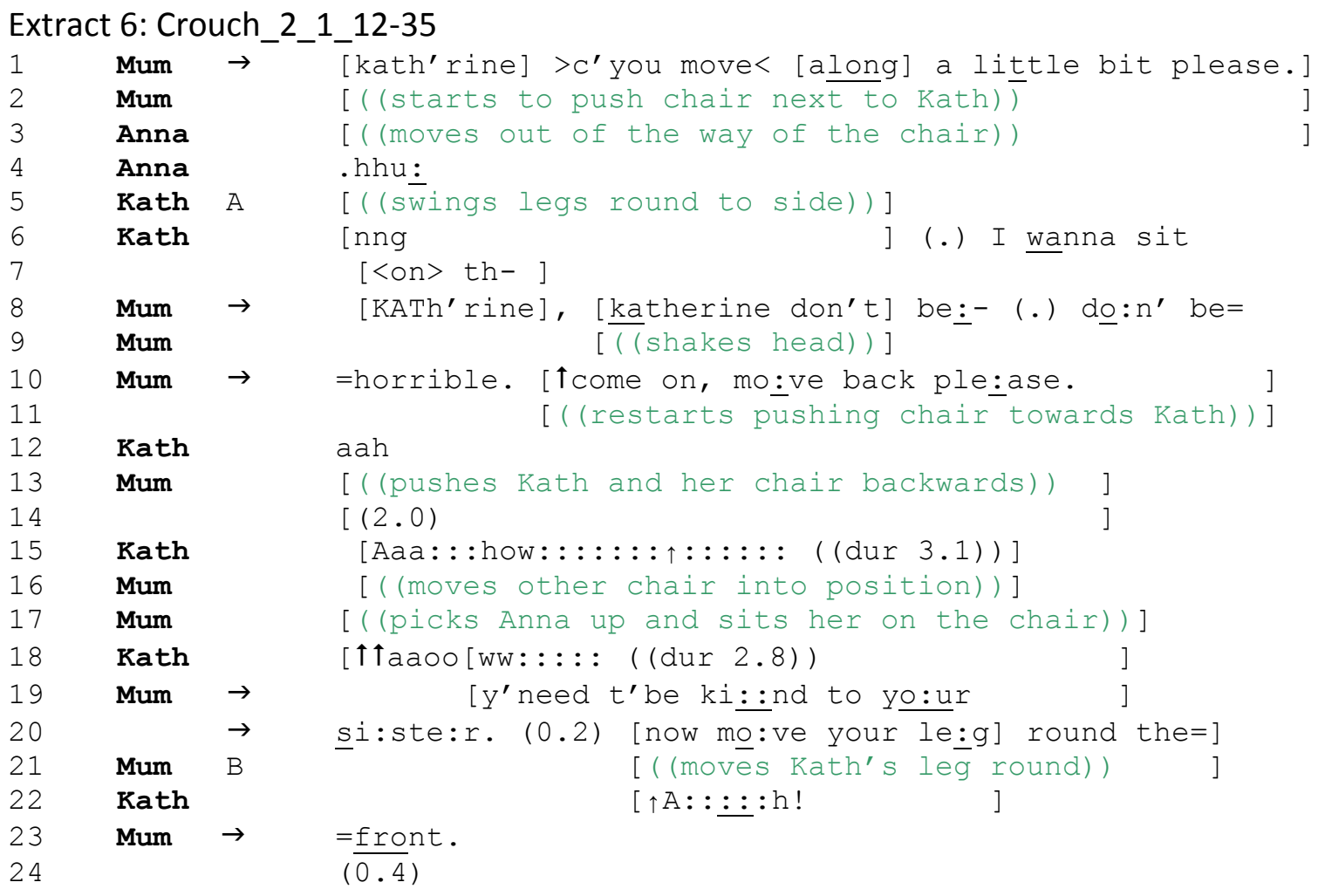




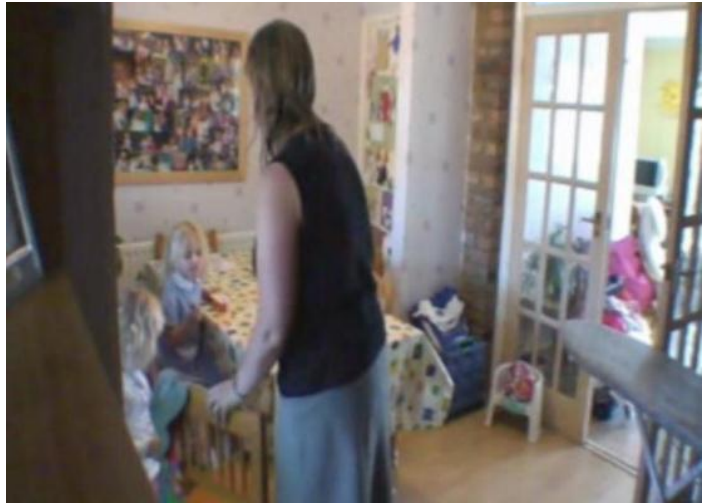

Image A: Line 5

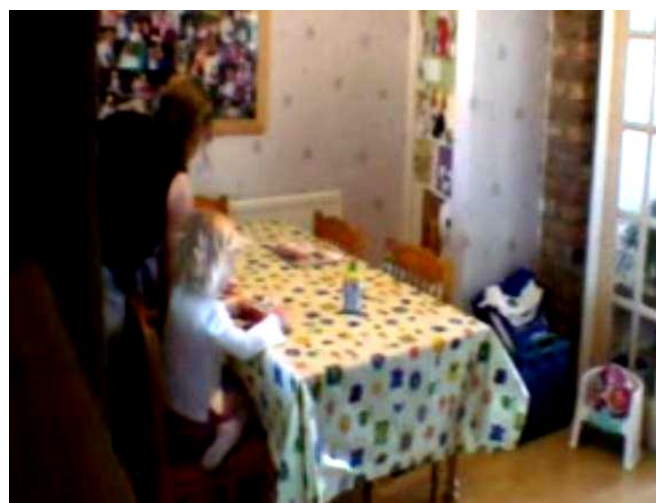

Image B: Line 21

In Extract 6 Katherine is sitting on her chair somewhat askew. In line 1 Mum's turn takes the form of a request: "kath'rine] >c'you move< [along] a little bit please.]". If we break this up into elements, it comprises: (a) a turn initial address term; (b) a modal construction that formulates the recipient's capacity (can/could you); (c) a description of the requested action with a downgrade element (move along a little bit); (d) a terminal politeness item that also helps mark this as a request for action rather than an interrogative.

Note that between co-present parties a request of this kind can simply and visibly be granted by the recipient performing the requested action in the slot directly after the request, where the action would be most relevant. In this case Katherine swings her legs round to where Mum wants to place the chair (line 5-Image A). That is, in the slot directly after the request, her movements display the opposite of compliance. In addition to this, Katherine provides an account which starts to specify her wants: I wanna sit $[<0 n>$ th(line 6). That is, Katherine's account specifies precisely the kind of personal capacity or desire that Curl and Drew (2008) show is typically referenced in modal request forms. We can see the symmetry between using modals in requests and using them in accounts - each specify the relevant issues in the granting and rejecting of requests.

Katherine's move on line 5-7 is uncooperative in that it does the opposite of compliance. Mum breaks into it before it is complete with a turn that now has more the 
character of directive than a request. Note that there are two differences of environment for this directive: (a) it follows a display of non-compliance with the previous request and (b) Katherine's legs are now in even more of a problematic position for placing the chair.

Let us now consider the construction of Mum's directive - the redone request - in lines 8 and 10:

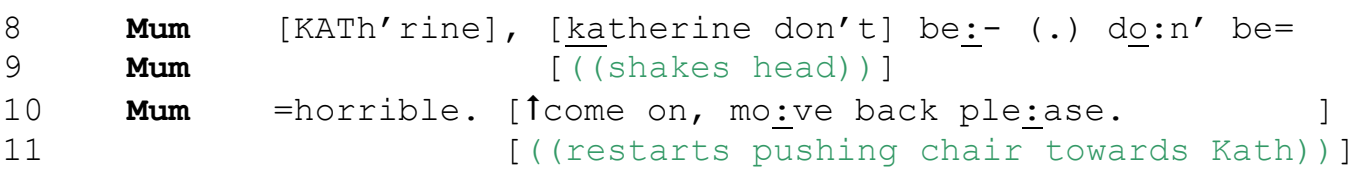

This has a number of elements: (a) the repeated summons/address term, (b) the formulation of what Katherine is doing as 'horrible' and a directive not to be horrible, (c) what we can call a cajoling token or a prompt for compliance - 'come on', which may also serve to reference Mum's earlier requests as 'not done and in need of doing', (d) the directive construction 'move back', and finally (e) a terminal politeness marker, and action marker, 'please'.

Now note that some elements of the initial request no longer appear in this construction. Relevantly, now the modal form is not used. Thus Mum says ' $\mathrm{do}_{\underline{0}} \mathrm{n}$ ' be horrible.' rather than using a modal such as 'can you not be horrible'; and she says 'mo: ve back' rather than using a modal such as 'will you move back'. In addition, the moderating element 'a little bit' has been dropped. By dropping the modal form from the construction Mum removes the contingency of the 'can/could you' modal interrogative in the earlier request. In showing less concern with contingent elements such as the recipient's capacity or willingness she heightens her display of entitlement to direct her daughter's actions. 
Mum's turn in lines 8 and 10 provides several opportunities for compliance.

Katherine could move her legs around during or after the naming, the formulation of her non-compliance as horrible, the 'come on', the directive, or the politeness marker. Billig (1998) has shown with respect to parent-child interaction, admonishments, moral condemnations and instructions can provide both a guide to what is bad and an indication of how to accomplish being bad. They set up a new matrix of constitutive possibilities. Katherine's leg position becomes more than a comfortable way of sitting. It is an account for not granting Mum's request. By line 11 it is something actively bad. Furthermore, the upgraded expression of entitlement shown in Mum's switch from request to directive provides the possibility for what comes after to be not refusing a request but defying a directive. Indeed, in this case Katherine takes none of the opportunities to comply, thus leaving herself in the position of having defied the directive.

At this point something interesting and complicated happens. Mum moves from verbally directing Katherine to physically moving her (Image B). Katherine accompanies this with extended indignant sounding cries on lines 15 and 18. This is perhaps a limit case of minimizing contingency and maximizing the display of entitlement. By physically moving Katherine into position she is given (almost) no possibility to avoid compliance. No contingency is open here. Moreover by physically moving Katherine, Mum completely takes over the agency for the relevant action. The asymmetry in entitlement is thus maximized. It is hard to think of a stronger display of entitlement over the actions of the other than to physically move them into place. Mum does issue a further verbal directive on lines 20 and 23. This has no modal construction; it combines an imperative - mo : ve your le:g round the front. - with a curt sounding 'now' (which perhaps upgrades the cajoling but encouraging $\uparrow_{\text {come on }}$. However, given the coordination with the physical movement of 
Katherine by Mum it is hard to see how any further compliance could be given. At this point Mum leaves no space for Katherine to comply independently.

The overall pattern we see in this sequence is a move from a construction similar to Curl and Drew's (2008) classic modal request form (line 1) to a bald directive form that has no interrogative element (lines 8-10). Finally the move is to physically shifting the recipient's limbs into the required position (line 21). This transition steadily heightens entitlement (the speaker's right to make the request and to expect compliance) throughout the sequence. At the same time, acknowledgment of the recipient's will/ability (what Curl and Drew call contingency) steadily diminishes and disappears.

Let us explore this further with another example in which multiple directives appear. In the following extract we see a similar upgrading of the directive as in the previous example.

Extract 7: Crouch_2_5_36-49

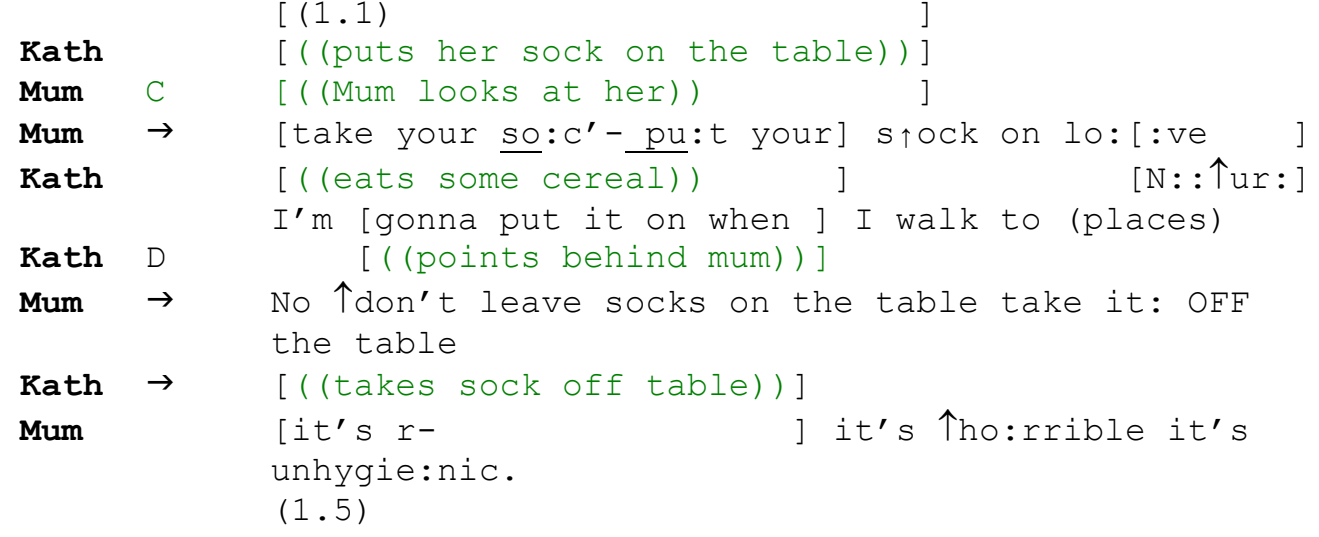




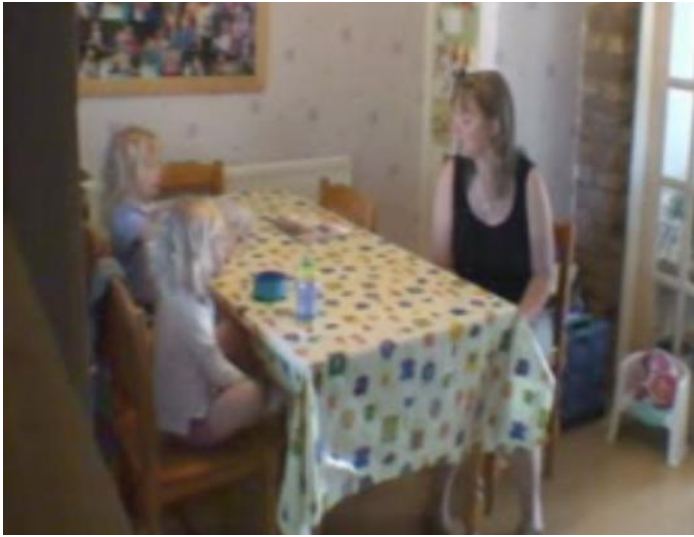

Image C: Line 3

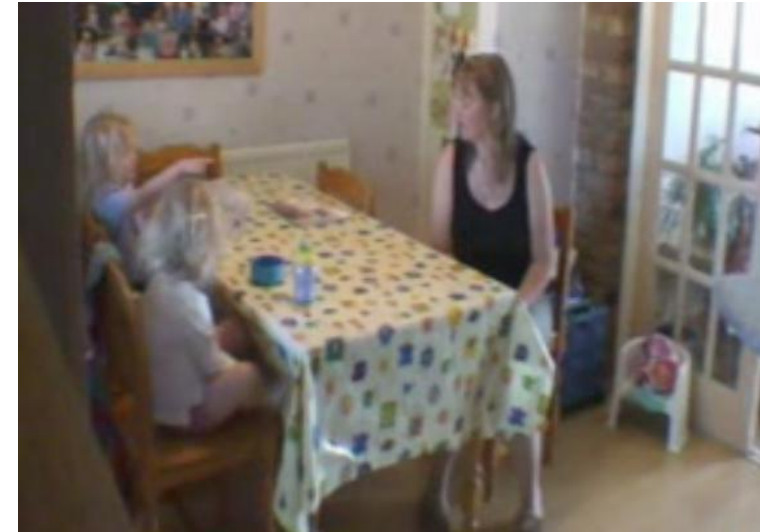

Image D: Line 7

At the start of the extract Katherine puts her sock on the table. Earlier in the meal the video shows her taking the sock off her foot. Mum's look at line 3 may be a display of looking (Heath \& Luff, 1998) that provides an opportunity for Katherine to change her conduct without verbal direction from Mum. Whether it is, or not, and whether Katherine treats it like this, or not, she does not take the sock off the table. At line 4 Mum issues a

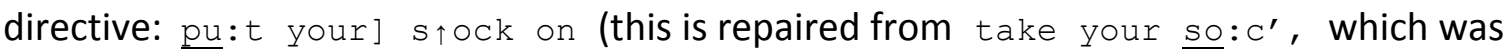
presumably headed for 'take your sock off the table'). The directive finishes with a term of endearment: $10:[:$ ve, in turn-final position.

Terms of endearment such as 'love' may serve to display the status of the relationship between the two speakers. Therefore, it may make relevant Mum's parental status and so heighten her entitlement to direct. Moreover, by foregrounding the strongly affiliative nature of the familial relationship, the term of endearment could serve to moderate the impositional force of the directive.

Again, consider what is absent from this turn. There is no modal construction: would/could/will you put your sock on. Nor is there a wondering: I am wondering if you would put your sock on. As before then, there is nothing that makes compliance with the 
directive contingent on the recipient's capacities or desires. There is no projection of refusal as an appropriate responsive action to Mum's initiating action.

In line 5-6 (the space for complying or refusing the directive) Katherine decisively rejects it. Not only does she preface the rejection with the hard and early $\mathrm{N}:$ : $\uparrow$ ur: (partly overlapping the mother's term of endearment) but she explicitly describes a course of action that she is going to take that is contrary to the directed one - " $I$ ' $m$ [ gonna put it on when ] I walk to (places)".

This rejection provides the environment for Mum's next directive on line 8. Like Katherine's rejection it is prefaced by a turn-initial 'no'. Mum's "No" on line 8 explicitly disagrees with Katherine's justification on lines 5-6. Like the " $\uparrow$ come on" in Extract 6, it rejects Katherine's turn as an acceptable response and reissues the original directive It is interesting (if somewhat tangential) to note the two examples here of immediate and unhedged or mitigated dispreferred responsive actions; (a) Katherine's refusal to comply with Mum's directive, and (b) Mum's rejection of Katherine's refusal. This marks the action organization here as a departure from more standard forms. Again, we might speculate that this is reflection of the sorts of asymmetries that exist between parent and young child; although it may be that it is in forms like this that the recognisable asymmetry is constituted.

Mum's turn initial 'no' on line 8 is followed by two directives. The first is 'script formulated' (Edwards, 1994, 1997); that is, the tense and plural produce the directive as a general injunction about socks and tables. The second directive follows immediately after the first. There is, then, no sense that Mum is waiting to see if the first has been effective. Indeed, the scriptedness of the first directive may be more focused on the future oriented lesson than the immediate problem of this sock. The second directive moves back from the 
plural to singular and thereby from the scripted to the immediate and specific. It is more focussed than the first and projects the action more strongly. There is also a considerable increase in volume of 'OFF' which makes this directive sound more insistent than the first one. $^{1}$

As in Extract 6, we can see here that subsequent directives do not orient to further or heightened contingency; if anything the directives become more insistent. At the same time there is no lowering of the expressed entitlement to have the directive acted on; Mum treats herself as able to appropriately direct her daughter's actions. Finally, after Katherine has removed her sock, Mum provides a strongly assessing account for the requirement that socks should not go on the table - placing a sock on the table is formulated as both '个ho:rrible' and 'unhygie:nic.' . Her accounts come after the directive has been acted on. Therefore, they are not produced as a persuasive case that will eventuate in sock removal.

Our general observation is that in the directive sequences found in the mealtime data, non-compliance with directives recurrently leads to upgraded (more entitled and less contingent) repeat directives ${ }^{2}$. Whereas second requests can orient to a new trajectory brought about by the recipient's choice to refuse the request, second directives tended not to acknowledge the recipient's right not to comply and so upgraded the directive to further restrict the optionality of response solely to compliance. For example in Extract 6 Katherine begins to express a desire ("I wanna sit" line 6), but is cut off by Mum's second directive on lines 8-10. By preventing Katherine from delivering a response, Mum can reissue the directive without orientation to the contingencies that may have been expressed in Katherine's response. In Extract 7, Katherine is able to fully formulate a turn resisting the directive (line 6). Here Mum explicitly rejects that turn ("No") and then upgrades her 
directive. In both cases the potential for a contingency to change the trajectory of the talk is prevented from doing so.

We further explicate the effect of not allowing non-compliant responses to shift the trajectory of the ongoing sequence in Extract 8. Prior to the extract all four family members have been discussing an upcoming school nativity play.

Extract 8: Forbes_6_1_2-25 (Lucy = 5 years, Daisy = 8 years $)$
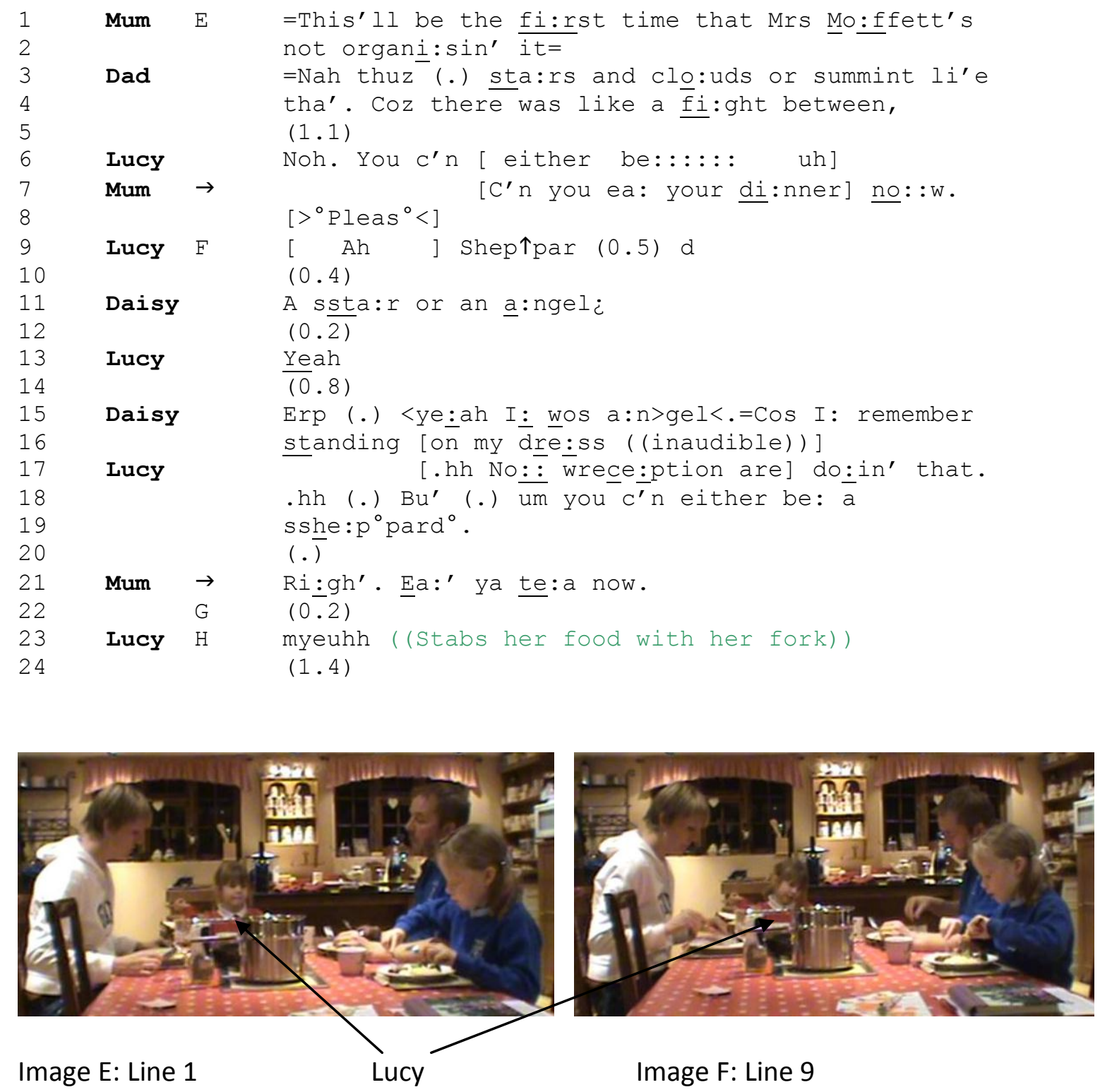


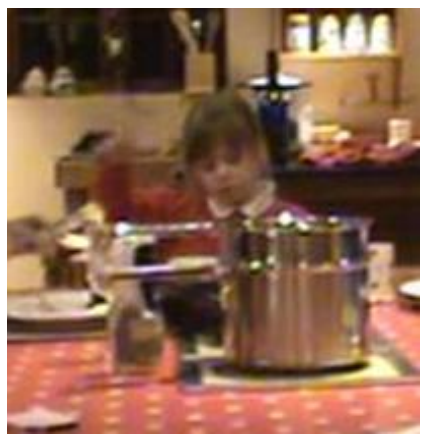

Image G: Line 22

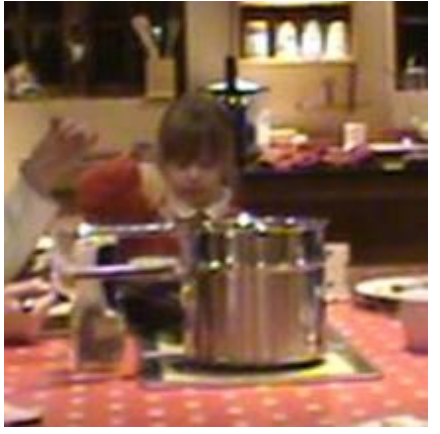

Image H: Line 23

On line 7 Mum breaks into Lucy's turn to deliver a directive. Lucy continues to speak and both utterances are delivered in overlap. Mum's directive can be clearly heard despite the overlap because, for the most part it lies on top of Lucy's extended "be: : : : : : " sound (line 6).

Mum uses the modal form of the directive " [ $C^{\prime} n$ you ea: your di: nner] no: : w. $\left[>^{\circ} \mathrm{Pleas}{ }^{\circ}<\right] "$ (line 7-8). The modal form orients to potential contingencies affecting Lucy's ability / willingness to eat her dinner. However, the "no: : w." treats such contingencies (including perhaps the ongoing conversation about Lucy's Nativity play) as no longer an appropriate reason not to be eating. The closing intonation on the "no: : w." makes the turn-final " $>{ }^{\circ} \mathrm{Pleas}{ }^{\circ}<$ " into something of an increment, spoken more quietly and quite quickly it is hearable as a later addition. Despite the modal construction, elements like the "no: : w." and "> ${ }^{\circ}$ Pleas ${ }^{\circ}<$ " mark this as a directive rather than a request. It projects compliance rather than acceptance or refusal.

Lucy's talk is built as non-responsive to the first directive. The position of Lucy's fork; hand in a limp wrist pointing over her shoulder away from the table does not change following the first directive (images $\mathrm{E}$ and F); it remains in a stance that does displays no orientation to eating. 
If Lucy was in any doubt about the appropriate response to Mum's utterance in line 7, Mum's second utterance is upgraded to an imperative form, leaving less room for confusion or evasion - “Ri:gh'. Ea:' ya te:a now.” (line 21). Mum's directive on line 7 was delivered in overlap with Lucy's talk. Mum waits until the sequence that Lucy's turn launches comes to a close before reissuing the directive. The second directive is prefaced with the discourse marker "Ri $\underline{\underline{g} g h^{\prime}}$. ", which is indicative of a shift in topic (Jefferson, 1993). This specifically separates the upcoming talk from that which precedes it. The modal formulation has been replaced by the imperative "Ea :'", which does not project refusal as a possible response option. It thereby heightens the sense of Mum's entitlement to direct Lucy. The second directive shortens "your di : nner" to "ya te: a", making the second directive quicker and curter to utter. The shorter utterance may carry an increased sense of urgency. $^{3}$

Although Mum's second directive (line 21) is delayed, it does not orient to the

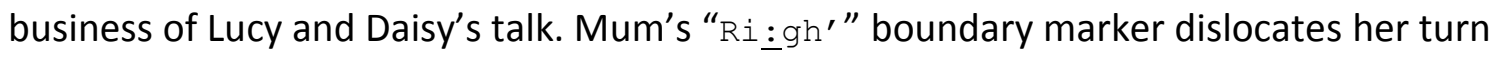
from the talk that has taken place in the position where a response to her first directive should have been. Lucy's response to the second directive is to immediately fling her arm round so her fork is in position to pick up food and comply with the directive (images $\mathrm{G}$ and H).

In the next extract we again see Mum avoiding orientations to responses to her directives that do not display compliance. In Extract 9 Emily and Jessica are eating chocolate and Mum is waiting for them to finish. Jessica has a handful of foil wrapped chocolate balls and Emily has a train shaped chocolate lollipop. Prior to the extract Emily has been making her chocolate lollipop dance across the table like a train. 
Extract 9: Amberton_10_5_48-88 (Jessica = 4 years, Emily $=7$ years)

1

2

Emily

Jess J
Emily

Mum $\rightarrow$

Emily

Mum

Emily

Jess $K$

Emily

Emily

Emily

Mum $\rightarrow$

Jess

Emily

Emily

Mum

Emily

Jess

Mum

Emily

Jess

Mum

Emily

Mum

Emily

Mum $\rightarrow$

[ (1.6)

[( (puts chocolate in her mouth briefly then takes it out and stretches back to towards Jessica))

((stretches over to meet Emily in the middle))]

${ }^{\circ}$ ' $n$ ' $O: N$ ABo[a: :rd ] [chh ] [chh]

[can we:] ea: [t it] [ple]a: :se

chh chh [chh chugh ] [else I shall]

[( (bang bang) ) ] ( (bang))

$[(0.6)$

[( promptly eats her chocolate in one go))]

[( (moves her chocolate to her mouth but doesn't take a bite))

$[((\mathrm{nod}))] \quad[((\mathrm{nod}))]$

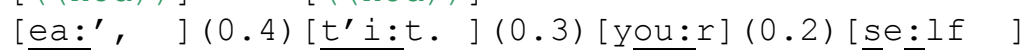

$(0.8)$

$[>\overline{\text { now }}<] \quad[$ plea:se $]$

$\mathrm{m}(\mathrm{h}) \mathrm{m}: \mathbf{:} \mathrm{m}$

$(4.4)$

${ }^{\circ} \mathrm{hmmm}^{\circ}$

(2.1)

whu:l1 (0.6) I li:ke this >because< (0.5) when i(.) you: get in d- dis $\uparrow 1$ i:ttle ma:n it goe- gets (0.3) thi $:$ cke:r

$\mathrm{mm}$ Thmm.

thick (0.3) thick (0.3) thi(.) ck (0.2) ck ex:r er e:r

$\overline{[}(1.1)$

[( (looks down $))$

((looks at Jessica))]

oh ka: :y?

(1. 9)

${ }^{\circ} \mathrm{muh}^{\circ}$

((turns to look at Emily))

$\mathrm{m}: \mathrm{um}$ :

uh $\bar{h} u: h$

no- not $>$ ma< mul mmy.

(1.1)

$\frac{\text { ea }}{(0.7)}$ plea : : se

41

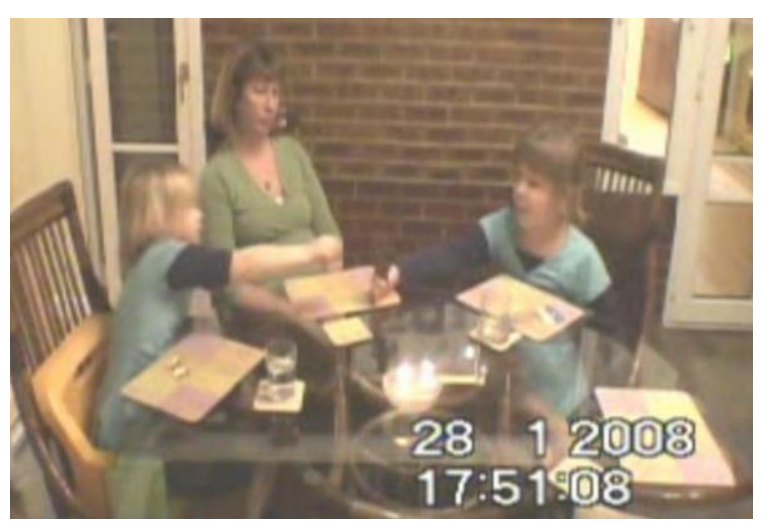

Image J : Line 5

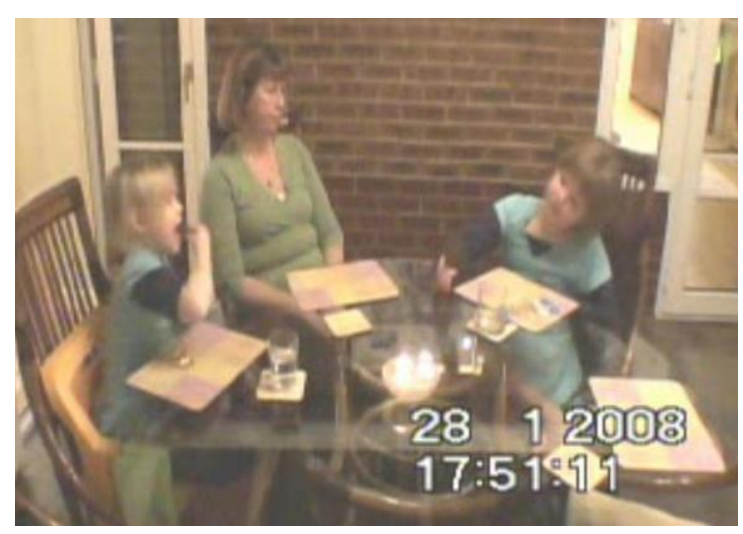

Image $\mathrm{K}$ : Line 12 
At the start of this extract Emily and Jessica are playing trains with their respective chocolates. It's a relatively physical activity for the dinner table and involves stretching across Mum, who is sitting between them (image J). On line 7 Mum issues the directive "can we: ] ea: [t it] [ple] a: :se" in overlap with Emily's train noises. This directive is composed of a) a modal request form that orients at least notionally to Emily's ability to comply, b) "we $]^{3}$ ", an inclusive plural person of the verb that includes all parties at the table and minimises the ' $I$ ' $m$ telling you what to do' sense of the turn, c) an indexical referent to the lollipop as "it" and finally d) a please in turn final position, referencing politeness conventions, the reasonableness of Mum's request, and the moral obligation to behave politely.

In response to this directive Emily continues to play trains with her food, even through and beyond Mum's increment, which starts to build a threat "else I shall" (line 9) (cf. Hepburn and Potter, under editorial consideration). Jessica then swiftly complies (line 12) (image K), but Emily only partially complies by moving the chocolate towards her mouth (line 13) before defying the directive and telling Mum to "[ea:' $\left.{ }^{\prime}\right](0.4)$ [t'i:t. ] (0.3) [you:r] (0.2) [se:lf]" (line 16).

Mum's second directive " $[>\underline{\text { now }}<] \quad[p \underline{\text { lea }}$ : se $]$ " is delivered on line 17 in overlap with Emily's response. The overlap itself embodies Mum's entitlement by showing a lack of orientation to Emily's talk. This directive also drops the modal formulation and the inclusive "we" construction. The new time element "now" references the 'not done' nature of the earlier directive. It increases the urgency of the directive. Finally the turn-ending "please" is retained, possibly highlighting the normative moral and politeness conventions that Emily's defiance is flouting. ${ }^{4}$ 
The second directive upgrades the speaker's entitlement by no longer using a modal construction to orient (even notionally) to Emily's ability or willingness to comply. It also reduces the available contingencies by specifying a time frame rather than leaving that to the discretion of the recipient. By reducing orientation to contingencies and heightening the entitlement claimed, we can see that this extract also follows the upgrade pattern identified for directives.

On line 23, instead of complying with Mum's second directive Emily announces that she likes the chocolate lollipop. Her turn begins with "whu: 11 ", which typically signals a dispreferred second pair part (Pomerantz, 1984). Her explanation for liking the lollipop does not orient to its status as 'to be eaten' or food related in any way. Emily is hearably doing non-compliance. She continues to not comply by engaging in rhythmic word play until line 39 when Mum delivers a third directive. This directive is just as pared down as the second, but this time exchanging the time element (which Emily has demonstrably been defying since it was issued) with the imperative verb "ea $: t$ ".

The third directive restricts the possible contingencies one step further. Emily's wordplay is a potential contingency affecting compliance - if Mum is endorsing the play activity through the beat of her words and compliance would interrupt the word play, then it can be used as a contingency. The third directive no longer follows the rhythmic pattern of Emily's speech, marking Mum's now total disengagement with the play frame that she had, at least tokenly, oriented to through mirroring Emily's beat in her earlier directive. Just as the second directive did not orient to Emily's challenge, the third does not orient to either the 'reasons for liking chocolate lollipop's' topic or the word sound games. By not orienting to the wordplay, Mum systematically ignores these contingencies in her sequential building of the directives. 
In Extracts 8 and 9 we have seen how second directives do not orient to responsive actions other than compliance. This provides some evidence that while requests may project acceptance or refusal, directives project solely compliance and fully restrict 'refusal' response options by not allowing them space to progress the interaction along a new trajectory. By not accommodating recipient's non-compliant responses, repeated directives display the speaker's ongoing lack of concern with contingencies affecting compliance never mind that Emily was playing a word game, she had been told to eat her chocolate. Throughout the extracts shown, the speaker's lack of accommodation for new trajectories in the talk was accomplished through a number of devices:

a) reject the responsive action outright ("No" - Line 8 Extract 7),

b) reference the 'not yet done' nature of the first directive, thereby making the second directive a reissued version of the first rather than a new turn following simple sequential relevance ("Come on" - Line 10 Extract 6, and "Now" - Line 17 Extract 9), or

c) mark the conversation as having reaching a boundary, thereby making clear that what come next is not built on that which immediately precedes it ("Right" in Extract 8 Line 21).

What we see here is that subsequent directives do not acknowledge the recipient's right not to comply. Instead, they upgrade the directive to further restrict the optionality of response. They pursue compliance and suppress other alternatives. The features of directives outlined here (high entitlement, low contingency, and movement to polarise both 
dimensions in any subsequent repeats) are the basis for our suggestion that, when imposing on another participant's behaviour, directives claim the right to tell, not just to ask.

\section{Discussion}

This paper aims to explicate some of the basic features of directives in terms of the management of contingencies and the level of entitlement claimed.

In the first analytic section we considered some of the features of simple directives such as:

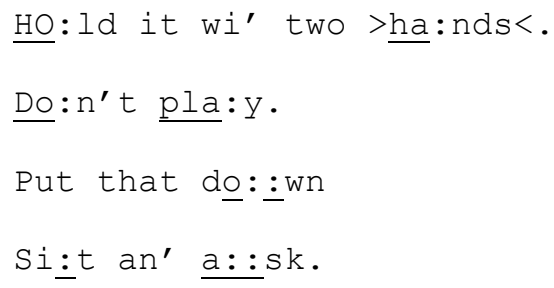

Each of these directs the recipient's conduct by telling them what to do or not to do. In these cases the recipient is directly told to do something rather than asked using a modal construction (can you...) or addressed with a wondering (I wonder if you can...) as in Curl and Drew's (2008) analysis of requests. In directives, performing the stated action is not treated as contingent on the capacity or desires of the recipient. At the same time, the lack of attention to issues of capacity and desire (by not embodying these issues in a modal request form) builds a strong display of the speaker's entitlement to direct the recipient's actions.

It is relevant to note that a recurrent feature of directives in our corpus was that they would interrupt the recipient's talk mid-TCU and overlap their turn rather than waiting for a TRP (Sacks et al, 1974). For example: 

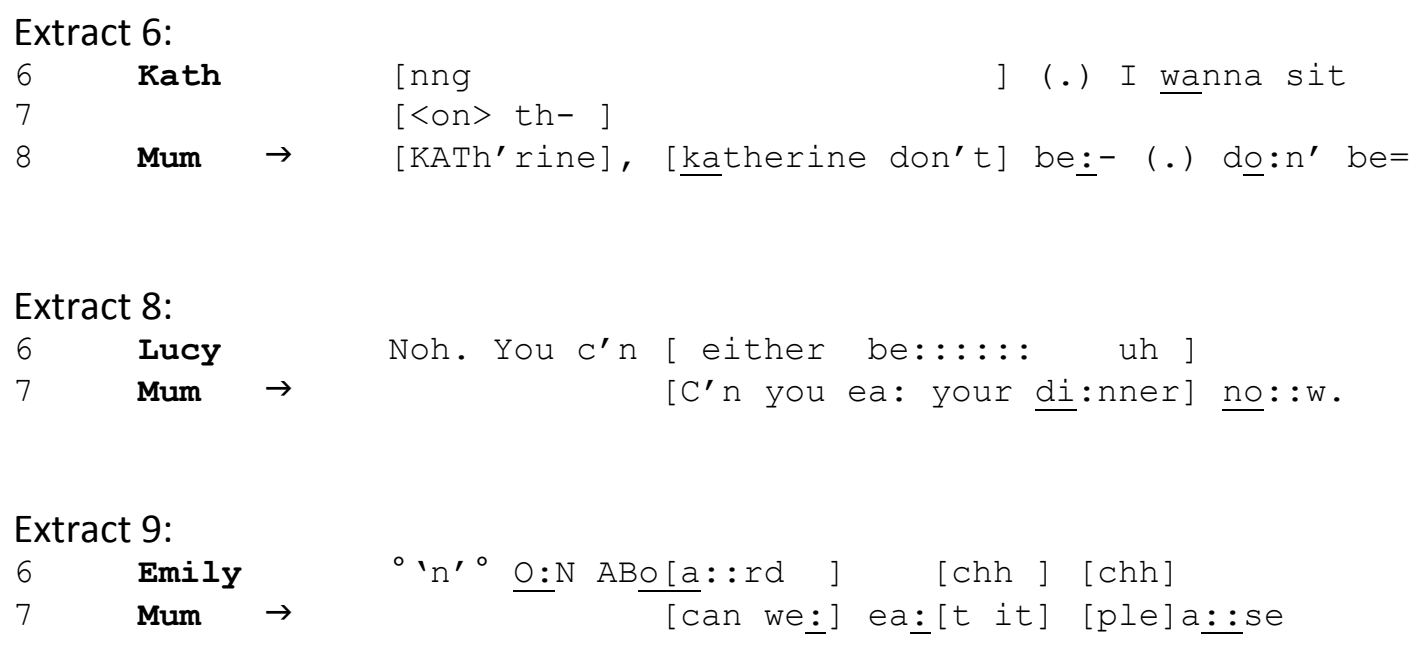

By disregarding normative turn-taking conventions and issuing a directive as an interruption, speakers of directives display a lack of orientation to the recipient's talk. This can be used to particular effect in directives/requests formulated as modal such as in Extracts 8 \& 9: Here the talk, which ostensibly orients to the recipient's capacities and desires can still be built as competitive to the course of action they are engaged in. In this sense it embodies the directive speakers entitlement over the recipient's actions, including their contributions to the interaction within the turn-taking structure.

Directives work to actively reduce or manage contingencies during the delivery of the directive. Unlike requests, they are not structurally designed to project non-compliance on the basis of being unwilling or unable to comply. In treating contingencies as under their control, rather than as a resource of the recipient, the speaker further enhances his or her display of entitlement.

In virtue of their interrogative form, requests have the relevance of acceptance built into them - although explicit acceptance can be replaced by actual conduct in line with the request. Directives, in contrast, do not have acceptance as a relevant next action. This is part of what makes their display of entitlement so strong. The talk of the speaker who issues the directive (in this case the parent) is not oriented to acceptance; their talk orients 
entirely on compliance. Not only is the speaker displaying their right to impose on the recipient, they are also claiming the right to bypass the recipient's right to refuse that imposition. In a sense, the entitlement claimed is 'to tell' not just 'to ask'.

Given the centrality of the notions of contingency and entitlement to the analysis it is worth spending a bit more time considering what is involved in these notions. The central idea of contingency is that when a request is issued, its granting is dependent on factors outside the speaker's direct control. Request forms strongly orient to these factors being the domain of the recipient by using interrogative and modals that typically foreground the capacities (can forms) or desires (want forms) of the recipient. In contrast, the directives in our collection do not attend to the capacities or desires of the recipient. Following the directed course of action is not built as something that is contingent.

This inattention to recipient's capacities or desires is highlighted in sequences such as Extract 6 above where a reissued directive follows explicit expressions of desires that run counter to the directive's thrust. When the sequence starts with a bald directive there is no move to back down to more request patterned forms even after the recipient shows resistance or defiance. Instead, the directive is upgraded (lower contingency and higher entitlement) using a variety of means (e.g. volume, lexical choice and intonation).

It is of course relevant to note here that these directives are issued by parents to their children. When a parent ignores the child's display of desires that run counter to the directive, they display their entitlement to manage and direct the actions of their child. It will be interesting to see in studies of directives in other settings, with possibly fewer assumptions of asymmetry, how far the features that are endemic here are repeated. Curl and Drew (2008) argue that the difference between modals and wondering + modal forms displays a difference of entitlement. Where entitlement is low, such as 
phoning an out of hours medical service about a minor ailment, then a wondering is more likely to be used. Where the entitlement is high, such as when asking a family member to bring a letter to a prearranged meeting, then the modal form is more likely to be used. We suggest that in both of these cases, through the modal (whether interrogative or not) there is an orientation to the recipient's capacities or desires. What is striking about the directives we have discussed here is that they orient to neither capacity nor desire. In the extreme case this does not just involve verbally directing, but issuing threats, or physically moving the recipient to the required position.

In addition to the pattern of upgraded entitlement and downgraded contingency in repeat directives, we also noted the associated lack of orientation to potential new trajectories in the talk following non-compliance with the first directive. By blocking new trajectories and referencing the first saying of the directive, second directives in a sequence have more the character of a repeated utterance rather than a new, successive turn at talk. Schegloff (2004) looked at dispensability in repeated utterances. He suggested that "by retaining a turn-initial marker, the speaker reclaims the sequential position the first saying occupied and marked by that turn-initial marker" (2004: 142). His data was primarily related to repair sequences, where the conversation could be 'dialled back' to the point where confusion occurred and redone from that point onwards. On the basis of the examples above we might suggest that in second directives the addition of a turn-initial marker such as 'right', or 'come on' can also work towards reclaiming the sequential position of the first directive, with the associated affect of deleting the recipient's non compliant response. Similarly the lack of orientation in second directives to actions following the first directive contribute to the sense that the intervening action is discarded and the directive is re-done as the same thing in different words (Schegloff, 2004). 
It is important to note that, although hearable as re-doings of the same thing, second sayings take place in a different environment to first sayings (Schegloff, 2004). Many of the features that we argue show heightened entitlement do so because they draw on the 'not done' nature of the directive that exists upon its second saying where it did not during the first. This makes producing a second directive hearable as a repeat a useful resource for speakers. In terms of entitlement to direct another person's actions, the very fact of asserting that right for a second time when it has already been refused could be taken as a heightened sense of entitlement: To tell someone to do something once is presumptuous enough, but to tell someone to do something when they have just refused to comply raises the implied sense of entitlement still further.

Finally, it is no accident that our directive-rich material comes from family mealtimes where we have examples of parents interacting with young children at mealtimes. Here the purpose of the interaction, 'eating the meal', is highly task oriented and therefore more likely to generate directive formulations (Vine, 2009). From this preliminary work it is possible to identify at least three important avenues of future work.

First, it will be important to look systematically at the relationship of directives to related actions such as threats and body manipulation. These are recurrent features of our materials and further work will be needed to establish how far these actions are more extreme forms of directives and how much they have their own social organisation. Initial work with threats suggests they have a complex organisation of their own (Hepburn and Potter, under editorial consideration).

Second, it will be interesting follow up the organisation of directives in other task based setting such as classrooms, therapy sessions, or driving lessons, where the institution 
provides for different potential asymmetries (of authority, of knowledge) between the participants.

Third, it will be interesting to study the involvement of directives with family organization and the way their use can display orientations to different desires, competences and entitlements of children. It may provide a practical interaction-based pathway to address core issues of child development and social organization. This may ultimately be a different and more interactionally concrete way into the topic of socialization.

\section{References}

Aronsson, K. and Thorell, M. (1999). 'Family politics in children's play directives'. Journal of Pragmatics, 31: 52-47.

Billig, M. (1998). 'Rhetoric and the Unconscious'. Argumentation, 12: 199-216.

Charles, N. and Kerr, M. (1985). 'Food, and Families'. Manchester: Manchester University Press.

Curl, T. and Drew, P. (2008). 'Contingency and action: A Comparison of Two Forms of Requesting'. Research on Language and Social Interaction, 41(2), pp. 129-153.

Drew, P. (2008). Conversation analysis. In J.A. Smith (Ed.). Qualitative psychology: A practical guide to research methods, $2^{\text {nd }} E d$ (pp. 133-59). London: Sage.

Edwards, D. (1997). Discourse and Cognition. London: Sage.

Edwards, D. (1994). Script Formulations: A Study of Event Descriptions in Conversation. Journal of Language and Social Psychology, 13: 211-247. 
Edwards, D. \& Potter, J. (2001). 'Discursive psychology'. In A.W. McHoul and M. Rapley (Eds). How to analyse talk in institutional settings: A casebook of methods (pp. 1224). London: Continuum International.

Ervin-Tripp, S. (1976). 'Is Sybil there? the structure of some American English directives'. Language in Society, 5: 25-66.

Fasulo, A., Loyd, H. and Padiglione, V. (2007). 'Children's socialization into cleaning practices: a cross-cultural perspective'. Discourse and Society, 18: 11-33.

Goodwin, M.H., (1980). Directive-Response Speech Sequence in Girls' and Boys' task activities. In: S. McCommell-Ginet, R. Borker and N. Furman, eds, Women and Language in Literature and Society. London: Praeger, pp. 157-173.

Goodwin, M.H. (1990). He-Said-She-Said: Talk as Social Organisation Among Black Children. Indianapolis: Indiana University Press.

Goodwin, M.H. (2006). 'Participation, affect, and trajectory in family directive /response sequences'. Text and Talk, 26: 515-543.

Grieshaber, S. (1997). 'Mealtime rituals: power and resistance in the construction of mealtime rules'. British Journal of Sociology, 48: 649.

Heath, C.C. and Luff, P. (1996). 'Convergent Activities: Line Control and Passenger Information on London Underground'. In D. Middleton and Y. Engeström (Eds.). Cognition and Communication at Work: Distributed Cognition in the Workplace (pp. 96-129). Cambridge: Cambridge University Press.

Hepburn, A. and Potter, J. (under editorial consideration). Threat: Power, family mealtimes and social influence.

Huddleston, R. and Pullum, G.K. (2005). A Student's Introduction to English Grammar. Cambridge: Cambridge University Press. 
Hutchby, I. and Wooffitt, R. (2008). Conversation Analysis, $2^{\text {nd }}$ Ed. Cambridge: Polity Press. Jefferson, G. (1993), Caveat Speaker: Preliminary Notes on Recipient Topic-Shift Implicature, Research on Language and Social Interaction, 26, 1, 1-30.

Lareau, A. (2002). 'Invisible Inequality: Social Class and Childrearing in Black Families and White Families'. American Sociological Review, 67: 747-776.

Pomerantz, A. (1980). 'Telling My Side: 'Limited Access' as a 'Fishing' Device'. Sociological Inquiry, 50: 186-198.

Pomerantz, A. (1984). 'Agreeing and disagreeing with assessments: some features of preferred/dispreferred turn shapes'. In J.M. Atkinson and J. Heritage (Eds). Structures of Social Action: Studies in Conversation Analysis (pp. 57-101). Cambridge: Cambridge University Press.

Sacks, H., Schegloff, E.A. and Jefferson, G., (1974) A simplest systematics for the organisation of turn-taking for conversation, Language, 50, 4, pp696 - 735

Schegloff, E.A. (1996). 'Turn Organisation: one intersection of grammar and interaction'. In E. Ochs, E.A. Schegloff and S.A. Thompson, eds, Interaction and Grammar. Cambridge: Cambridge University Press, .

Schegloff, E. A. (2007). Sequence organization in interaction. Volume 1, A primer in conversation analysis. Cambridge: Cambridge University Press.

Searle, J.R. (1979). Expression and Meaning: Studies in the Theory of Speech Acts. Cambridge: Cambridge University Press.

van der Auwera, J. and Lejeune, L. (with Goussev, V.). (2008). The Prohibitive. In M. Haspelmath, M. S. Dryer, D. Gil, and B. Comrie, eds, The World Atlas of Language Structures Online. Munich: Max Planck Digital Library, chapter 71. Available online at http://wals.info/feature/71. Accessed on 2009-12-11. 
Vine, B. (2009). 'Directives at Work: Exploring the contextual complexity of workplace directives'. Journal of Pragmatics, 41: 1395-1405.

Wingard, L. (2006). 'Parents' inquiries about homework: The first mention'. Text and Talk, 26: 573-596.

Wootton, A. (1997). Interaction and the Development of Mind. Cambridge: Cambridge University Press.

\section{Notes}

The use of scripted directives, and the difference between immediate and future oriented directives is clearly a significant issue for families. It relates to the local sequential organisation of what would traditionally be called socialisation. It is however, beyond the scope of this paper to address this here.

The increase in entitlement of successive directives bears an intriguing similarity to Pomerantz' observation that 'early attempts display the participant's orientation to propriety ('fishing'), whereas successive attempts may have that orientation relaxed and take the form of [more] direct requests' (Pomerantz, 1980: 198). Much like Pomerantz (1980) did, we note this trend as a preliminary observation; it will require further work to fully unpick the mechanics of upgraded repeated action.

It's worth mentioning here that the word change from 'dinner' to 'tea' could manage the potential contingency (albeit perhaps remote) that Lucy did not understand 'dinner'. If so, the change fits into the identified upgrade pattern by managing or removing contingencies without orienting to them or giving them voice.

The turn-final "plea:se" is the only element retained across all three directives. This might serve to reinforce the aberrant, inappropriate nature of Emily's behaviour by working up the reasonableness and politeness of Mum's turns without restricting her ability to upgrade her entitlement to direct. It is hard to pin down exactly how 'please' fits into the dimensions of entitlement and contingency. It would be worthwhile as a topic of further study to investigate the use of please in directive/request sequences in terms of its impact on entitlement and contingency. 